\title{
CORRECTION
}

\section{Correction to: Superconducting Transport Properties of NiFe Artificial Spin Ice and Nb Hybrid Structure}

\author{
Apoorva Verma $^{1,2} \cdot$ Mandeep Kaur $^{1} \cdot$ T. D. Senguttuvan ${ }^{1,2} \cdot$ Anurag Gupta $^{1,2}$ \\ Published online: 31 August 2021 \\ ๑) Springer Science+Business Media, LLC, part of Springer Nature 2021
}

Correction to: Journal of Superconductivity and Novel Magnetism (2021) 34:373-381

https://doi.org/10.1007/s10948-020-05707-8

The original version of this article unfortunately contained a mistake in the affiliation section. Thus, this erratum is presented to fix this error.

The original article has been corrected.

Publisher's Note Springer Nature remains neutral with regard to jurisdictional claims in published maps and institutional affiliations.

The original article can be found online at https://doi.org/10.1007/ s10948-020-05707-8.

Anurag Gupta

anurag@nplindia.org

1 CSIR-National Physical Laboratory, Dr. K. S. Krishnan Marg, New Delhi 110012, India

2 Academy of Scientific and Innovative Research (AcSIR), Ghaziabad 201002, India 